\title{
Appetite suppressants and primary pulmonary hypertension in the United Kingdom
} S H L Thomas, A Y Butt, P A Corris, J J Egan, T W Higenbottam, B P Madden,
P C Waller

\author{
Wolfson Unit of \\ Clinical \\ Pharmacology, \\ University of \\ Newcastle upon Tyne, \\ Newcastle \\ S H L Thomas \\ Papworth Hospital, \\ Papworth Everard, \\ Cambridgeshire \\ A Y Butt \\ T W Higenbottam \\ Freeman Hospital, \\ Newcastle \\ P A Corris \\ North West Lung \\ Centre, Wythenshawe \\ Hospital, Manchester \\ J J Egan \\ Harefield Hospital, \\ Harefield, Middlesex \\ B P Madden \\ Medicines Control \\ Agency, London \\ $P C$ Waller \\ Correspondence to: \\ Dr S H L Thomas \\ Wolfson Unit of Clinical \\ Pharmacology, University \\ of Newcastle upon Tyne, \\ Newcastle NE1 6RU. \\ Accepted for publication \\ 24 July 1995
}

\begin{abstract}
Objective-Amphetamine-like appetite suppressants, particularly fenfluramines, have been implicated in the aetiology of primary pulmonary hypertension. At one specialist centre in France $20 \%$ of patients with primary pulmonary hypertension had been exposed to fenfluramine. The prevalence of primary pulmonary hypertension associated with fenfluramines and other appetite suppressants in the United Kingdom is unknown. This study was performed to measure prior exposure to appetite suppressants in patients with primary pulmonary hypertension.
\end{abstract}

Setting-Heart lung transplantation centres in England.

Patients-United Kingdom residents with proven primary pulmonary hypertension referred for consideration of heart lung transplantation.

Methods-Case surveillance study, obtaining data from the hospital and general practitioner's notes and directly from the patients or their relatives.

Results-55 patients were identified. Drug histories were available from hospital records in all patients, from the general practitioner's notes in 51, and from the patients or relatives in 44 . Of these, 3 female patients had been exposed to appetite suppressants ( 2 fenfluramine, 1 diethylpropion): 2 have since died. In each case exposure was brief and apparently predated the development of symptoms by several years.

Conclusions-Exposure of patients with severe primary pulmonary hypertension to fenfluramine and other appetite suppressants is uncommon in the United Kingdom unlike in France, where most of the cases associating primary pulmonary hypertension with fenfluramine use have originated. This may reflect more conservative prescribing of these agents in the United Kingdom.

(Br Heart f 1995;74:660-663)

Keywords: appetite suppressants; fenfluramine; diethylpropion; pulmonary hypertension

Primary pulmonary hypertension is characterised by an increase in pulmonary artery pressure and plexogenic pulmonary arteriopathy. This usually results in relentlessly progres- sive breathlessness and eventual death. Epoprostenal (prostacyclin) or calcium channel blockers may improve symptoms and prolong survival. ${ }^{1}$ The alternative treatments heart lung, lung, or double lung transplantation are limited by donor organ supply. The aetiology of primary pulmonary hypertension is unknown but drugs may be implicated in some patients. There was an epidemic of primary pulmonary hypertension after the introduction of the appetite suppressant aminorex in Europe $\mathrm{e}^{2-4}$ and there have been several additional reports suggesting a link between primary pulmonary hypertension and other amphetamine-like drugs including propylhexedrine; $;^{5}$ phendimetrazine tartrate; ${ }^{6}$ the combination of $\mathrm{d}$-amphetamine, phenmetrazine, diethylpropion, and phentermine; ${ }^{7}$ and (dl) fenfluramine $e^{8-11}$ or its dextro-enantiomer dexfenfluramine. ${ }^{12-14}$ Recently, exposure to fenfluramines was found in $15(20 \%)$ of 73 patients with primary pulmonary hypertension referred to a French specialist centre. ${ }^{15}$ Oral contraceptives ${ }^{16}$ and biguanide anti-diabetic drugs ${ }^{17}$ have also been linked to primary pulmonary hypertension, although the evidence is less compelling.

A role for fenfluramines and related drugs in the aetiology of primary pulmonary hypertension is biologically plausible: fenfluramines, particularly dexfenfluramine, provoke the release and block the subsequent cellular uptake of serotonin, a pulmonary vasoconstrictor. ${ }^{18-20}$ Indeed, potentiation of serotonin within the brain seems to be the key mechanism for their anorexiant effects. ${ }^{21}$ In rats, high doses of fenfluramines have induced acute fatal pulmonary hypertension. ${ }^{22}$ It is therefore important to determine the possible role of fenfluramines and other anorexiants in the aetiology of primary pulmonary hypertension.

The use of fenfluramines has increased in the United Kingdom since the introduction of dexfenfluramine in $1989 .{ }^{23}$ To examine the possible extent of the hazard to public health from these and related substances, exposure of British patients with primary pulmonary hypertension to appetite suppressants was determined by a retrospective case-surveillance study.

Patients and methods

All United Kingdom residents with primary pulmonary hypertension over 14 years of age who had been referred to four heart lung transplantation centres in England (Harefield, 
Table 1 Clinical features of the 55 patients with primary pulmonary hypertension

\begin{tabular}{lll}
\hline Variable & $\begin{array}{l}\text { Mean } \\
(S D)\end{array}$ & Range \\
\hline Blood gases (on air) & & \\
$\mathrm{pH}$ & $7 \cdot 44(0 \cdot 05)$ & $7 \cdot 32-7 \cdot 9$ \\
$\mathrm{Po}_{2}(\mathrm{kPa})$ & $8 \cdot 7(2 \cdot 5)$ & $4 \cdot 1-16 \cdot 7$ \\
$\mathrm{PCO}_{2}(\mathrm{kPa})$ & $3 \cdot 8(0 \cdot 7)$ & $2 \cdot 4-5 \cdot 7$ \\
Lung function (\% predicted) & & \\
FEV & $79(14)$ & $64-108$ \\
$\mathrm{FVC}$ & $85(14)$ & $67-114$ \\
$\mathrm{KCO}$ & $70(20)$ & $19-101$ \\
TLC & $97(16)$ & $76-149$ \\
Pulmonary artery pressure (mm $\mathrm{Hg})$ & $95(16)$ & $60-125$ \\
Systolic & $42(11)$ & $25-60$ \\
Diastolic & $61(12)$ & $37-89$ \\
Mean & $63(10)$ & $36-82$ \\
Mixed venous oxygen (\%) & \\
\hline
\end{tabular}

$\mathrm{FEV}_{1}$, forced expiratory volume in $1 \mathrm{~s} ; \mathrm{FVC}$, forced vita capacity; KCO, carbon monoxide transfer factor; TLC, total lung capacity.

Newcastle, Papworth, Manchester) for possible heart lung transplantation during the three year period January 1990-December 1992 were evaluated. This included those who died and those who received a transplant.

Primary pulmonary hypertension was defined as an increase in pulmonary artery pressure $(>40 / 20 \mathrm{~mm} \mathrm{Hg}$ or mean $>25 \mathrm{~mm}$ $\mathrm{Hg})$ associated with characteristic lung histology (when available) and a normal left heart and mitral valve. Exclusion criteria included evidence of primary lung disease from lung function tests (forced expiratory volume in one second, forced vital capacity, and peak expiratory flow rate); pulmonary embolic disease detected by pulmonary angiogram, ventilation-perfusion scan, or high resolution computerised tomography scan; significant shunt detected by cardiac catheterisation; or doubt about the diagnosis. Patients with primary pulmonary hypertension and right to left shunting through a patent foraman ovale were not excluded.

Details of the patient's medical history, drug history, hospital investigations, and treatment were extracted from the hospital notes including, when necessary, those of the referring hospital. A detailed drug history was sought from the general practitioner and directly from the patients. If the patient had died, information was sought from their next of kin and from the general practitioner's notes via the medical director of their local Family Health Service Authority.

Ethical approval for the study was obtained

Table 2 Exposure of primary pulmonary hypertension patients to cigarettes, oral contraceptives, and appetite suppressants

\begin{tabular}{lllc}
\hline Exposure & Yes & No & Inadequate data \\
\hline Smoking & $23(43 \%)$ & 30 & \\
Ever smoked & $15(28 \%)$ & 38 & 2 \\
Smoking at diagnosis & $28(70 \%)$ & 12 & 1 \\
Oral contraceptives (females, $\mathrm{n}=41)$ & $17(55 \%)$ & 14 & 10 \\
Any & $21(68 \%)$ & 10 & 10 \\
Oestrogen-containing & 0 & 54 & 1 \\
Progesterone-containing & $3\left(6 \%{ }^{\star}\right)$ & 51 & 1 \\
Oral hypoglycaemics (any) & $2\left(4^{\star}\right)$ & 52 & 1 \\
Appetite suppressants (any) & 1 & 53 & 1 \\
Fenfluramine & 0 & 54 & 1 \\
Diethylpropion & 0 & 54 & \\
Dexfenfluramine & 0 & 54 & \\
Phentermine & Mazindol & &
\end{tabular}

${ }^{\star} 95 \%$ Confidence interval $0.3 \%$ to $11 \%$ (any appetite suppressant) and 0 to $8 \%$ (fenfluramine). from the joint ethics committee of Newcastle Health Authority and the University of Newcastle upon Tyne.

\section{Results}

Sixty nine patients with possible primary pulmonary hypertension were located from the four participating centres, of whom 14 were subsequently excluded (three under 14 years, one presenting outside the study dates, two with previous pulmonary embolism, three resident abroad, and five with inadequate documentation). The 55 patients who met the entry criteria (14 males, 41 females, (table 1)) included eight patients with small atrial septal defects or a patent foramen ovale identified on echocardiography on at least one occasion. Only one of these had a shunt demonstrated at echocardiography or cardiac catheterisation and this was trivial (left to right, 1·3:1). Also included were two patients with systemic sclerosis, one patient with a positive rheumatoid factor without lung involvement, one patient with an inconsistently weakly positive anticardiolipin antibody (without evidence of thromboembolism), and two unrelated patients with hereditary primary pulmonary hypertension. At the time of final data collection (August 1994) 32 were alive $(58 \%), 23$ dead $(42 \%$, mean interval from diagnosis to death 18 months), and $11(20 \%)$ had received heart lung transplants.

Data were available from the hospital notes in 55 patients, from general practitioner's records in $51(91 \%)$, from the patient or next of kin in $44(80 \%)$, from two different sources in $55(100 \%)$ patients, and from all three sources in $39(71 \%)$.

Only three women exposed to appetite suppressants were detected: two (4\%) exposed to fenfluramine (Ponderax) and one (2\%) to diethylpropion (Tenuate Dospan). The first patient was exposed to fenfluramine for at least four months when aged 16 but did not develop breathlessness and syncope until aged 23. She died two years later. The second patient had an additional possible cause for pulmonary hypertension, systemic sclerosis associated with Raynaud's phenomenon. At 38 years of age she was prescribed fenfluramine for at least six months, although the total duration of exposure is unknown. She did not develop symptoms until 15 years later and at the time of diagnosis her lung function tests were abnormal (forced expiratory volume in 1 second and forced vital capacity about $50 \%$ of the predicted values). She died 18 years after exposure. The third patient was prescribed diethylpropion, three tablets daily for 3-5 months, when aged 22 and denied any consumption since. Breathlessness on exertion developed when she was 27 and she was diagnosed as having primary pulmonary hypertension four years later.

Of the 41 female patients, $70 \%$ had taken oral contraceptives at some time in their lives (table 2), primarily combined preparations with a low or intermediate oestrogen dose. No patient was identified as receiving biguanides. 


\section{Discussion}

In this study patients with primary pulmonary hypertension were identified at heart lung transplant centres. The advantages of this approach are that patients with this diagnosis are concentrated in these centres and have undergone extensive investigations to exclude other possible causes of pulmonary hypertension. However, they are a highly selected group of patients with particularly severe and irreversible disease. It is possible that drugs may cause milder, reversible or rapidly lethal forms of primary pulmonary hypertension and such patients may never be referred for consideration of transplantation. A further disadvantage of studying severely affected patients is that a large proportion had died and their drug histories, obtained from relatives, may be less reliable.

The study did identify patients with severe primary pulmonary hypertension exposed to fenfluramines, but they represented a smaller proportion of patients with this diagnosis (4\%) than in a French study, where $15 / 73(20 \%$, $95 \%$ confidence interval $13 \%$ to $28 \%$ ) of patients were exposed. ${ }^{15}$ It is reassuring that exposure to appetite suppressants in each of these three United Kingdom cases seemed short-lived and predated the development of symptoms by several years, although the possibility remains that the two patients who took fenfluramine might have obtained further supplies privately: this would not have been apparent from the general practitioner's notes. One of the two fenfluramine cases also had another possible cause for pulmonary hypertension, systemic sclerosis. The study therefore suggests that fenfluramines and other appetite suppressants are infrequently associated with severe irreversible primary pulmonary hypertension in the United Kingdom, although the possibility remains that exposure may be higher in less severely affected patients.

The discrepancy between these results and those of the French study might be explained by differences in prescribing pattern between the two countries, such as higher overall consumption, or use of higher doses or longer treatment courses of fenfluramines in France, although we have no data to confirm or refute this. British doctors are discouraged from using diethylpropion and phentermine and have been advised that fenfluramines should not be used for longer than three months. ${ }^{1424}$ Another possible reason for the discrepancy is that some patients with primary pulmonary hypertension induced by appetite suppressants may improve after these drugs are stopped and may not be referral to a transplant centre. This explanation seems unlikely because the French patients with primary pulmonary hypertension associated with appetite suppressants had similar mean pulmonary artery pressures $(57 \mathrm{~mm}$ $\mathrm{Hg}$ ) to those unexposed patients with primary pulmonary hypertension $(63 \mathrm{~mm} \mathrm{Hg}$ ) and the patients studied here $(61 \mathrm{~mm} \mathrm{Hg})$ and, in addition, only three of the 15 exposed French patients improved after fenfluramines were stopped.
It was originally planned to expand this research into a case-control study, however, the numbers of exposed cases identified are insufficient to demonstrate a link between primary pulmonary hypertension and appetite suppressants, regardless of the level of exposure in the control group. Collection of cases over several more years would be needed to achieve reasonable statistical power. In addition, large numbers of controls would be needed to make an accurate estimate of exposure in the general population and matching these for age, sex, general practitioner, and body weight, would be difficult. The ongoing International Primary Pulmonary Hypertension Study ${ }^{25}$ is a multinational case control study which addresses this question and may provide a more definitive answer.

These data suggest that severe primary pulmonary hypertension associated with appetite suppressants is less common in the United Kingdom than in France. There is no room for complacency, however, as prescribing of the fenfluramine drugs has increased in the United Kingdom since the introduction of dexfenfluramine and, if there is a link, the number of cases of primary pulmonary hypertension may increase as a result.

We are grateful to the many general practitioners, patients and relatives for taking the time to supply us with the information presented here. We also thank $\operatorname{Dr} A$ Woodcock for helping to identify suitable patients at the Wythenshaw Hospital, Manchester.

1 Butt AY, Higenbottam T. New therapies for primary pulmonary hypertension. Chest 1994;105 (suppl 2):21S-5S. Follath F, Buckart F, Schweizer W. Drug-induced pulmonary hypertension. Br Med F 1971;i:265-6.

3 Kay JM, Smith P, Heath D. Aminorex and the pulmonary circulation. Thorax 1971;26:262-70.

4 Loogen F, Worth H, Schwan G. Long-term follow-up of pulmonary hypertension in patients with and without pulmonary hypertension in patients with and

5 Cameron J, Waugh L, Loadsman T, White P, Radford DJ. Possible association of pulmonary hypertension with an Possible association of pulmonary hyperten
anorectic drug. Med $\mathcal{F}$ Aust 1984;140:595-7.

6 Nall KC, Rubin LJ, Lipskind S, Sennesh JD. Reversible pulmonary hypertension associated with anorexigen use. Am F Med 1991;91:97-9.

7 Malmquist J, Trell E, Torp A, Lindstrom C. A case of drug-induced (?) pulmonary hypertension. Acta Med Scand 1970;188:265-72.

8 Douglas JG, Munro JF, Kitchen AH, Muir AL, Proudfoot AT. Pulmonary hypertension and fenfluramine. $\mathrm{Br} M e d \mathfrak{F}$ 1981;223:881-3.

9 Gaul G, Blazek G, Deutsh E, Heeger H. Ein fall von chronischer pulmonar hypertonie nach fenfluramineinnahme. Wein Klin Wochenschr 1982;22:618-21.

10 McMurray J, Bloomfield P, Miller HC. Irreversible pulmonary hypertension after treatment with fenfluramine. Br Med F 1986;292:239-40.

11 Pouwels HMM, Smeets JLRM, Cheriex EC, Wouters EFM. Pulmonary hypertension and fenfluramine. Eur Respir f 1990;3:606-7.

12 Atanassoff PG, Weiss BK, Schmid ER, Tornic M. Pulmonary hypertension and dexfenfluramine. Lancet Pulmonary hyp

13 Roche N, Labrune S, Braun J-M, Huchon GJ. Pulmonary hypertension and dexfenfluramine. Lancet 1992;i:436-7.

14 Committee on Safety of Medicines. Fenfluramine (Ponderax Pacaps), Dexfenfluramine (Adifax) and pulmonary hypertension. Current Problems 1992: No 34.

15 Brenot F, Herve P, Petitpretz P, Parent F, Duroux P Simmoneau G. Primary pulmonary hypertension and fenfluramine use. Br Heart $f$ 1993;70:537-41.

16 Kleiger RE, Boxer $M$, Ingram RE, Harrison DC Pulmonary hypertension in patients using oral contraceptives. Chest 1976;69:143-7.

17 Fahlen M, Bergmar H, Helder G, Ryden L, Wallentin I, Zettergren $\mathrm{L}$. Phenformin and pulmonary hypertension. Br Heart $\mathcal{f} 1973 ; 35: 824-8$.

18 Editorial. Dexfenfluramine. Lancet 1991;337:1315-6.

19 Neely CF, Haile D, Matot I. Tone-dependent responses of 5 -hydroxytryptamine in the feline pulmonary vascular 5 -hydroxytred are mediated by two different 5-hydroxytrystamin receptors. F Pharmacol Exp Ther 1993;264:1315-26.

20 Bradley JD, Zanaboni PB, Dahms TE. Species differences in pulmonary vasoactive responses to histamine, 5-hydroxy- 
tryptamine and KCl. $\mathcal{F}$ Appl Physiol 1993;74:139-46.

21 Turner P. Dexfrenfluramine. Its place in weight control. Drugs 1990;39 (suppl 3):53-62.

22 Hunsinger RN, Wright D. A characterisation of the acute cardiopulmonary toxicity of fenfluramine in the rat. Pharmacol Res 1990;22:371-8.

23 Thomas SHL, Campbell M. Prescribing of appetite suppressants in England: an inverse marker of prescribing quality? [abstr] Brf Clin Pharmacol 1995;38:97P.

24 British National Formulary No 28. London: British Medical Association and The Pharmaceutical Society of Great Britain. 1994, 173

25 Abenhaim L, Moride Y, Bégaud B. International case-control studies in pharmacoepidemiology: opportunities and methodological issues [abstr]. Pharmacoepidemiology and methodological issues [abstr]. Phar
Drug Safety 1994;3:(suppl 1):S73.

\section{ABSTRACTS IN CARDIOLOGY}

\section{Are the pineal gland and the heart closer than we think?}

A recent short report in the Lancet reported that there was impaired nocturnal secretion of melatonin (secreted by the pineal gland) in 15 patients with coronary artery disease compared with 10 healthy controls. Animal studies have shown that melatonin is involved in the suppression of sympathetic activity (reason not known). Melatonin was measured at 2 am and $2 \mathrm{pm}$ in all study subjects, and was found to be significantly lower at night in the coronary disease group, with no detectable secretion in either group during the day. No mention was made as to whether any drugs were being taken during the study.

Many prospective and retrospective studies have confirmed that patients with coronary artery disease (either overt or unknown) are more likely to suffer onset of acute myocardial infarction, sudden cardiac death, sustained and unsustained ventricular arrhythmias, thrombotic and haemorrhagic stroke, and transient myocardial ischaemia in the first few hours after waking and starting activities than at any other time of the day, and are least likely to suffer such events at night, a time of apparent "cardioprotection". This surge in morning (disease) activity corresponds with significant increases in blood pressure, heart rate, catecholamine release,

Impaired nocturnal secretion of melatonin in coronary heart disease

P Brugger, W Marktl, $M$ Herold

Patients with coronary heart disease have increased nocturnal urinary noradrenaline. Because melatonin suppresses sympathetic activity, we measured serum melatonin concentrations at night $(0200 \mathrm{~h})$ in 15 patients with coronary heart disease. Melatonin was significantly lower in the patients than in 10 healthy controls (median 7.8 [interquartile range $6.5-11.8]$ os 36.2 [32.2-42.5] pg/mL, $p<0.0001$ ). Thus, impaired nocturnal secretion of melatonin is associated with coronary heart disease. Lancet 1995;345:1408. peripheral vascular resistance, activation of the renin angiotensin system, and platelet aggregability during this period, and corresponds with the terminal trough in the endogenous fibrinolytic system. Almost all these responses are reproducible both in healthy controls and in patients with coronary artery disease.

While it is very difficult to tie in the findings of this small study with the clinical timing of cardiac events, and while all the clinical pointers suggest no such (measurable) increase in sympathetic activity in patients with coronary artery disease at night (which might have been expected were deficiency of melatonin to have resulted in increased sympathetic activity, as in Syrian hamsters), it may provide a possible explanation as to why ischaemic threshold appears to be reduced at night despite the recognised reduction in the determinants of myocardial oxygen demand at this time. Recent studies have shown that electrocardiographic ischaemia is reached at a lower threshold at night compared with the daytime, suggesting a nocturnal increase in coronary vasomotor tone in patients with stable coronary disease. This might also in part explain the propensity for patients with extreme alterations in coronary vasomotor tone (coronary spasm) to suffer transient occlusive events particularly in the early morning hours. A formal (blinded) trial assessing melatonin secretion, catecholamine concentrations, and sympathetic activity, particularly in patients with coronary spasm could help in putting the pineal gland more firmly on the cardiovascular map. In the meantime it seems doubtful that oral melatonin has got a place in assessing the development of coronary artery disease. All the patients with the abnormal melatonin response in the reported study already had coronary disease.

DAVID MULCAHY

1 Brugger P, Marktl W, Herold M. Impaired nocturnal secretion of melatonin in coronary heart disease. Lancet 1995;345:1408. 